\title{
Implementasi Program Keluarga Harapan dalam Meningkatkan Kesejahteraan Keluarga Miskin di Nagari Malampah Kabupaten Pasaman
}

\author{
Depi Zahrawati, Henni Muchtar \\ Program Studi Pendidikan Pancasila dan Kewarganegaraan \\ Universitas Negeri Padang \\ E-mail: Depi.zw@yahoo.com
}

\section{ABSTRAK}

Artikel ini bertujuan mendeskripsikan implementasi Program Keluarga Harapan (PKH) dalam meningkatkan kesejahteraan keluarga miskin sekaligus mendeskripsikan faktor penghambat dan pendukung keberhasilan implementasi program di Nagari Malampah Kecamatan Tigo Nagari Kabupaten Pasaman. Hal ini penting karena jumlah keluarga penerima bantuan PKH di Nagari Malampah lebih banyak dari nagari lain yang ada di Kecamatan Tigo Nagari. Penelitian ini menggunakan pendekatan kualitatif metode deskriptif. Subjek dalam penelitian adalah Kepala Dinas Sosial Kabupaten Pasaman, Koordinator Kabupaten, Pendamping PKH di Nagari Malampah dan masyarakat penerima bantuan PKH. Data kualitatif dikumpulkan melalui observasi, wawancara, dan studi dokumentasi kepada narasumber terkait. Hasil penelitan menunjukan bahwa pelaksanaan program keluarga harapan sudah berpatokan kepada peraturan menteri sosial nomor 1 tahun 2018. Namun dari masyarakat penerima bantuan PKH masih ada yang tidak berkomitmen terhadap kewajibannya seperti tidak menghadiri posyandu oleh ibu hamil dan anak usia 0-6 tahun, tidak menggunakan dana bantuan anak sekolah untuk keperluan pendidikan, tidak menghadiri pertemuan kelompok yang diadakan sebulan sekali. Faktor penghambat dan pendukung implemntasi program keluarga harapan dilihat dari komunikasi pendamping dan masyarakat sudah baik, sumber daya seperti staf dan fasilitas untuk nagari malampah masih kurang.

\section{Kata Kunci: Program Keluarga Harapan, Kesejahteraan, Keluarga Miskin}

\section{ABSTRACT}

This article aims to describe the implementation of the Family Hope Program (PKH) in improving the welfare of poor families while describing the inhibiting and supporting factors for the successful implementation of the program in Nagari Malampah, Tigo Nagari District, Pasaman Regency. This is important because the number of PKH beneficiary families in Nagari Malampah is more than other villages in Tigo Nagari District. This study uses a qualitative approach to the descriptive method. Subjects in the study were PKH Head of Pasaman Regency Social Service, District Coordinator, Community fasilitator and Community beneficiaries. Qualitative data were collected through observations, interviews, 
and study of documentation with relevant informants. The results of the research show that the implementation of the family of hope program is based on social ministerial regulation number I 2018. However, there are still PKH beneficiaries who are not committed to their obligations such as not attending posyandu by pregnant women and children aged 0-6 years, not using school children's assistance funds for educational needs, not attending group meetings which are held once a month. The inhibiting and supporting factors of the implementation of the family of hope program can be seen from the good communication between the companion and the community, resources such as staff and facilities for nagari Malampah are not enough.

\section{Keywords : Family Hope Program (PKH), Welfare, Poor Family}

\section{PENDAHULUAN}

Salah satu penghambat dalam pembangunan suatu negara ialah kemiskinan. Kemiskinan ada karena keterbatasan manusia dalam memenuhi kebutuhan hidupnya baik kebutuhan pangan, sandang, maupun papan. Di Indonesia kemiskinan selalu menjadi persoalan yang sangat krusial (Muslim Kasim, 2006:27). Berdasarkan data Badan Pusat Statistik (BPS) pada September 2018, penduduk miskin di Indonesia berjumlah 25,67 juta jiwa. Salah satu program percepatan penanggulangan kemiskinan dari pemerintah yaitu Program Keluarga Harapan (PKH). PKH diatur dalam Peraturan Menteri Sosial Nomor 1 Tahun 2018 yang merupakan program bantuan bersyarat yang diberikan kepada keluarga miskin yang terdaftar dalam data terpadu program penanganan fakir miskin dan memiliki 3 komponen yaitu pendidikan, kesehatan dan kesejahteraan sosial.

Bantuan sosial bersyarat yang dimaksud berhubungan dengan menjalankan kewajiban dan bekomitmen dengan kewajiban tersebut. Adapun kewajiban Keluarga Penerima Manfaat yaitu memeriksakan kesehatan pada fasilitas kesehatan sesuai dengan protokol kesehatan bagi ibu hamil/menyusui dan anak berusia 0 (nol) sampai 6 (enam) tahun, mengikuti kegiatan belajar dengan tingkat kehadiran paling sedikit $85 \%$ bagi anak usia sekolah wajib belajar 12 tahun, serta mengikuti kegiatan dibidang kesejahteraan sesuai dengan kebutuhan bagi keluarga yang memiliki komponen lanjut usia mulai dari 60 tahun dan/atau penyandang disabilitas berat. Penelitian tentang PKH penting dilakukan untuk menanggulangi kemiskininan dari titik terendah yaitu dari keluarga miskin. Dengan begitu akan memutus rantai kemiskinan antar generasi sehingga pembangunan suatu negara terus menuju kearah yang lebih baik.

Pasaman merupakan salah satu kabupaten yang ada di Provinsi Sumatera Barat yang melaksanakan Program Keluarga Harapan dengan jumlah penerima bantuan $\mathrm{PKH}$ sebanyak 12.854 PKH. Terdapat 12 Kecamatan yang semuanya menerima bantuan PKH. Kecamatan Tigo Nagari merupakan salah satu kecamatan yang ada di Kabupaten Pasaman yang mempunyai tiga kenagarian yaitu 
Nagari Malampah, Nagari Ladang Panjang, dan Nagari Binjai. Nagari Malampah mempunyai jumlah Keluarga Penerima Manfaat $\mathrm{PKH}$ terbanyak dari 2 kenagarian lainnya yaitu sebanyak 620 KPM. Program Keluarga Harapan di Nagari Malampah mulai dilaksanakan dari tahun 2015 sampai sekarang. Permasalahan yang ditemui dalam pelaksanaan program ini di Malampah yaitu keluarga penerima manfaat PKH tidak menghadiri layanan pemeriksaan kesehatan di posyandu oleh ibu hamil/menyusui dan anak 06 tahun, tidak menyekolahkan anaknya padahal masih usia sekolah wajib belajar 12 tahun dan tidak menggunakan bantuan pendidikan anak untuk keperluan sekolah melainkan kebutuhan lain. Masyarakat penerima bantuan PKH tidak berkomitmen dalam menghadiri pertemuan kelompok yang diadakan sebulan sekali, serta kurangnya tenaga pendamping yang ditugaskan di Nagari Malampah Kecamatan Tigo Nagari. Program Keluarga Harapan di Nagari Malampah masih belum berhasil. Hal ini dilihat dari data penerima bantuan $\mathrm{PKH}$ dari tahun 2015 sampai tahun 2019.

Tabel 1. Data Penerima Bantuan PKH di Nagari Malampah Pertahun

\begin{tabular}{|l|c|c}
\hline No & Tahun & Jumlah KPM \\
\hline 1 & 2015 & $326 \mathrm{KPM}$ \\
\hline 2 & 2016 & $326 \mathrm{KPM}$ \\
\hline 3 & 2017 & $276 \mathrm{KPM}$ \\
\hline 4 & 2018 & $356 \mathrm{KPM}$ \\
\hline 5 & 2019 & $620 \mathrm{KPM}$ \\
\hline
\end{tabular}

Sumber: Pendamping PKH di Nagari Malampah

Beradarkan Tabel 1 dapat dikatakan bahwa implementasi PKH masih belum berhasil. Keberhasilan program ini dilihat dari menurunnya angka kemiskinan dan meningkatnya kesejahteraan.
Penelitian terdahulu yang telah dilakukan oleh Oktaviani (2019) menunjukkan bahwa implementasi PKH pada realitasnya mengalami permasalahan dari pusat ke daerah serta dampak implementasi belum dirasakan secara optimal oleh masyarakat dari segi akses pendidikan dan kesehatan. Manongga, dkk (2018) yang meneliti mengenai implementasi PKH dalam mengatasi kemiskinan di Kelurahan Pinokalan Kota Bitung menunjukkan bahwa program pengentasan kemiskinan belum efektif sebab kurang menjamin peningkatan usaha produktif yang berkelanjutan bagi masyarakat miskin yang ditinjau dari komunikasi, sumber daya, disposisi, dan struktur birokrasi. Selain itu penelitian Permana, dkk (2018) di Kecamatan Lowokwaru Kota Malang menunjukkan bahwa implementasi pemberdayaan dalam pelaksanaan PKH adalah pembenahan kualitas hidup para peserta PKH dengan memperbaiki aspek kesehatan dan pendidikan keluarga. Selanjutnya penelitian Anggraini (2018) dengan judul faktor-faktor implementasi PKH di Kecamatan Sako Palembang menunjukan bahwa program ini kurang berhasil dikarenakan kurangnya tenaga pendamping $\mathrm{PKH}$ dan terdapat biaya tambahan akibat peralihan pembayaran melalui BRI. Penelitian lain juga dilakukan oleh Tirani (2018) dengan judul implementasi PK di Dinas Sosial Kabupaten Poso dimana hasil penelitian dilihat dari aspek komunikasi, sumber daya, disposisi dan birokrasi

Penelitan tersebut umumnya membahas mengenai implementasi Program Keluarga Harapan. Berbeda dengan penelitian yang peneliti 
lakukan yaitu mengenai implementasi PKH dalam meningkatkan kesejahteraan keluarga miskin serta faktor penghambat dan pendukung keberhasilan implementasi PKH. Penelitian ini penting dilakukan supaya dapat menjadi masukan bagi pemerintah pusat dan daerah dalam membuat dan meningkatkan $\mathrm{PKH}$ yang lebih baik guna menunjang kebutuhan keluarga miskin kedepannya.

Penulisan artikel ini bertujuan untuk mendeskripsikan implementasi PKH dalam meningkatkan kesejahteraan keluarga miskin di Nagari Malampah Kecamatan Tigo Nagari Kabupaten Pasaman dan mendeskripsikan faktor penghambat dan pendukung keberhasilan implementasi PKH. Manfaat secara teoritis diharapkan dapat menambah wawasan bagi pengembangan ilmu pengetahuan terutama dalam kajian ilmu sosial dalam pengentasan kemiskinan melalui PKH dalam meningkatkan kesejahteraan keluarga miskin. Manfaat secara praktis, bagi peneliti dapat menambah wawasan dan pengalaman langsung mengenai implementasi PKH dalam meneningkatkan kesejahteraan keluarga miskin. Masyarakat diharapkan dapat memberikan informasi kepada masyarakat agar tidak menyalahgunakan bantuan yang diperuntukkan bagi keluarga miskin dan memberikan informasi atas segala hasil yang penulis dapatkan berkenaan dengan implementasi PKH dalam meningkatkan kesejahteraan keluarga miskin. Bagi pemerintah hasil penelitian ini dapat menjadi informasi, masukan, dan sebagai bahan pertimbangan bagi pemerintah pusat maupun daerah dalam perencanaan
PKH dimasa yang akan datang supaya bisa meminimalisir kemiskinan yang ada di Indonesia.

\section{METODE PENELITIAN}

Jenis penelitian ini kualitatif dengan metode deskriptif. Penelitian dilakukan di Nagari Malampah Kecamatan Tigo Nagari Kabupaten Pasaman dengan alasan nagari ini merupakan nagari penerima bantuan terbanyak di antara nagari lain yang ada di Kecamatan Tigo Nagari. Pemilihan informan menggunakan teknik purpusive sampling dengan jumlah informan 21 Orang yang terdiri dari 1 Kepala Dinas Sosial Kabupaten Pasaman, 1 Koordinator PPKH Kabupaten Pasaman, 1 Wali Nagari Malampah, 2 Pendamping PKH Nagari Malampah, 4 Ketua Kelompok Keluarga Penerima Manfaat PKH, 8 Anggota Kelompok Keluarga Penerima Manfaat PKH dan 4 Masyarakat yang tidak menerima bantuan PKH. Jenis data yang digunakan yaitu data primer dan data sekunder. Data primer diperoleh langsung dari informan melalui wawancara, sedangkan data sekunder diperoleh dari hasil studi dokumentasi di lokasi penelitian. Teknik pengumpulan data dalam penelitian ini dilakukan melalui observasi, wawancara, dan studi dokumentasi, untuk menguji keabsahan data penelitian ini menggunakan teknik triangulasi sumber sebagai pembanding untuk mengecek kebenaran informasi yang didapatkan. Selanjutnya data yang diperoleh di analisis melalui tiga tahap, yaitu reduksi data, penyajian data dan menarik kesimpulan atau verifikasi. 
HASIL DAN PEMBAHASAN

\begin{tabular}{llrr} 
Implementasi & PKH & dalam \\
Meningkatkan & \multicolumn{2}{c}{ Kesejahteraan } \\
Keluarga & Miskin & di & Nagari \\
Malampah & & &
\end{tabular}

Pelaksanaan suatu program diperlukan struktur organisasi yang jelas (Charles O. Jones dalam Asna Aneta, 2010:59). Struktur Organisasi petugas PKH di Kabupaten Pasaman terdiri dari Koordinator Kabupaten, operator/ administrator pangkalan data dan pendamping PKH di Kecamatan. Sebelum program dilaksanakan ditentukan terlebih dahulu pelaksana program. Pelaksana program ditentukan oleh Kementerian Sosial dengan mengikuti beberapa tes telebih dahulu. Setelah lulus baru ditetapkan sebagai petugas atau pendamping PKH. Petugas PKH ditempatkan di Dinas Sosial bagian Sekrektariat PPKH tingkat Kabupaten. Pendamping PKH ditempatkan di Kantor Camat. Pengorganisasian Program PKH dilakukan pertingkat. Tingkat tertinggi dari Kementerian Sosial, Dinas Sosial Kabupaten/kota dan Kantor Camat. Petugas yang ditugaskan di kabupaten dikooordinatori oleh 1 orang koordinator atau disebut Koordinator PPKH kabupaten. Petugas yang ditempatkan di kecamatan disebut sebagai pendamping yang bertugas mendamping Keluarga Penerima Manfaat di lapangan. Pendamping PKH di kecamatan juga dikoodinator oleh 1 orang koordinator.

\footnotetext{
Pelaksanaan suatu program perlu ditafsikan agar menjadi pengarah dan rencana yang tepat supaya bisa dilaksanakan. Dalam implementasi program, interperetasi dilakukan dengan cara sosialisasi dan
}

pemberian informasi kepada para pelaksana. Sosialisasi dan pemberian informasi yang diberikan berhubungan dengan pelaksanaan kegiatan (Charles O. Jones dalam Asna Aneta, 2010:59). Sosialisasi PKH di Kabupaten Pasaman diberikan oleh kepala Dinas Sosial dan Koordinator PPKH Kabupaten Pasaman kepada para pendamping $\mathrm{PKH}$ terkait kegiatan pertemuan awal, validasi, verifikasi, penyaluran bantuan dan pemuthakhiran data. Selain memberikan sosialisasi dan informasi juga diberikan buku pedoman pelaksanaan $\mathrm{PKH}$ kepada masingmasing pelaksana untuk dijadikan pedoman dan patokan dalam melaksanakan tugasnya dilapangan supaya bisa mengetahui pelaksanaan PKH dengan jelas. Penyampaian informasi terkait komponen pendidikan, kesehatan dan kesejahteraan sosial dilakukan secara menyeluruh. Hal ini karena tidak semua kegiatan di bidang pendidikan, kesehatan dan kesejahteraan dicakup oleh PKH. Seperti pada bidang pendidikan hanya fokus untuk melihat tingkat kehadiran murid yang menerima bantuan PKH. Demikian juga bidang kesehatan hanya fokus pada tingkat kehadiran ibu hamil dan balita dalam kegiatan posyandu.

Pemberian sosialisasi juga dilakukan oleh pendamping $\mathrm{PKH}$ kepada masyarakat calon penerima manfaat PKH. Sosialisasi yang diberikan pada pertemuan awal dengan berhubungan dengan pengenalan tentang Program Keluarga Harapan serta kewajiban setelah mendapat bantuan PKH kepada masyarakat. Di Nagari Malampah, pemberian sosialisasi sangat sulit karena banyak masyarakat yang tidak 
menghadiri karena berbagai alasan yang mereka katakan seperti pergi ke kebun dan tidak ada yang mengurus anak/bayi dirumah serta saat bekerja ke kebun orang.

Menurut Charles O. Jones
(dalam Asna Aneta, 2010:59)

Penerapan atau aplikasi merupakan perwujudan dari pelaksanaan suatu program yang telah direncanakan sebelumnya. Dalam penerapan $\mathrm{PKH}$ terdapat mekanisme pelaksanaan diantaranya:

\section{a. Penetapan Sasaran}

Penetapan sasaran dilakukan dalam rangka perluasan jangkauan Keluarga Penerima Manfaat PKH yang didapat dari data terpadu program penanganan fakir miskin. Sasaran yang ditetapkan menjadi KPM PKH harus memiliki tiga komponen yang sesuai dengan Permensos No. 1 Tahun 2018 yaitu yang pertama keluarga yang dalam kategori miskin terdapat didalamnya ibu hamil atau menyusui dan anak usia 0 sampai 6 tahun. Kedua, terdapat anak usia sekolah wajib belajar 12 tahun yaitu SD, SLTP, dan SLTA. Ketiga, adanya lansia usia 60 tahun keatas atau disabilitas berat. Penetapan sasaran ini tidak bisa dirubah oleh pendamping karena sudah dikeluarkan langsung dari Kementerian Sosial. Namun jika ada perubahan data maka diselesaikan secara berjenjang mulai dari tingkat kecamatan, kabupaten, dan pusat.

b. Persiapan Daerah

Setelah ditetapkan lokasi yang akan menerima bantuan $\mathrm{PKH}$, maka daerah perlu menyiapkan beberapa hal diantaranya menyiapkan tim koordinasi teknis PKH yang berkoordinasi dengan tim koordinasi penanggulangan kemiskinan (TKPK), menyiapkan infrasutruktur seperti Petugas Program Keluarga Harapan yang ditempatkan di Dinas Sosial Kabupaten Pasaman bagian Sekretariat PPKH dan pendamping PKH yang ditempatkan di Kecamatan tepatnya di Kantor Camat. Setelah hal tersebut disiapkan maka dilakukan sosialisasi kepada tim koordinasi tingkat kabupaten, aparat pemerintah di kecamatan dan kenagarian, serta kepada masyarakat. Sosialisasi ini dilakukan supaya semua pihak yang telibat dalam program ini bisa mengetahui dengan jelas tentang $\mathrm{PKH}$ dan melaksanakan tugas dan tanggungjawabnya sebagai pelaksana program ini dengan baik.

\section{c. Pertemuan Awal dan Validasi}

Pertemuan awal dan validasi yaitu melakukan sosialisasi langsung kepada masyarakat calon Keluarga Penerima Manfaat (KPM) PKH dan mencocokkan data calon KPM PKH dengan kondisinya sekarang. Pertemuan Awal dilakukan sekali setahun dari Sekretariat PPKH kabupaten dan pendamping PKH yang ada di kecamatan. Sebelum melakukan pertemuan, pihak Sekretariat mengkoordinasi terlebih dahulu kepada pendampingpendamping yang ada di setiap kecamatan untuk menginformasikan kepada masyarakat calon KPM PKH.

\section{d. Penyaluran Bantuan PKH}

Penyaluran bantuan PKH dilakukan 4 tahap dalam setahun atau sekali dalam 3 bulan. Penyaluran bantuan PKH biasanya dilakukan di bulan Januari, April, Juni, dan Oktober. Setiap keluarga menerima bantuan yang berbeda-beda. Hal ini 
dikarenakan komponen yang ada dalam setiap keluarga juga berbeda. Di Kecamatan Tigo Nagari proses penerimaan bantuan PKH dilakukan di Kantor Camat. Pihak bank yang bersangkutan datang ke Kantor Camat pada tanggal penyaluran yang ditetapkan. Bank yang digunakan oleh KPM PKH di Kecamatan Tigo Nagari adalah bank Mandiri. Setiap daerah memiliki bank yang berbeda-beda pula tergantung pada kemudahana akses oleh daerah tersebut.

e. Pembentukan Kelompok KPM $\mathrm{PKH}$

Pembentukan kelompok

Keluarga Penerima Manfaat (KPM) PKH bertujuan untuk meningkatkan kemampuan KPM PKH. Pembentukan kelompok berdasarkan pada domisili atau tempat tinggal KPM PKH. Jika di daerah tersebut terdapat 40 lebih KPM PKH maka akan dibagi menjadi dua kelompok. Setiap kelompok mempunyai nama kelompoknya masing-masing dan mempunyai satu orang ketua kelompok. Ketua kelompok merupakan orang yang mewakili kelompok dan menjadi tempat penyelesaian masalah pertama bagi anggota KPM PKH dalam kelompok tersebut. Jika masalah tidak bisa diselesaikan oleh ketua kelompok, maka akan dilanjutkan ke pendamping yang mendampingi kelompok tersebut.

Di Nagari Malampah, setiap pertemuan kelompok diberikan materi yang berbeda-beda. Pemberian materi bertujuan untuk merubah pola fikir keluarga penerima manfaat supaya bisa meningkatkan kemampuannya. Kemampuan yang dimaksud yaitu mampu memahami materi yang disampaikan oleh pendamping ketika mengadakan pertemuan kelompok yang diadakan sebulan sekali dan mampu menerapkannya dalam kehidupan sehari-hari. Materi utama yang disampaikan oleh pendamping berupa modul Pertemuan Peningkatan Kemampuan Keluarga (P2K2) yang meliputi materi tentang kesehatan, pendidikan, ekonomi, perlindungan anak dan kesejahteraan sosial.

\section{f. Verifikasi Komitmen}

Verifikasi komitmen bertujuan untuk memantau tingkat kehadiran keluarga penerima manfaat $\mathrm{PKH}$ dalam menjalankan kewajibanya sebagai keluarga penerima manfaat PKH. Verifikasi komitmen dilakukan pada fasilitas kesehatan dan pendidikan secara rutin. Pelaksanaan verifikasi komitmen yang dilakukan oleh pendamping $\mathrm{PKH}$ di Nageri Malampah dilakukan sebelum penyaluran bantuan. Verifikasi komitmen dilakukan ke bidan desa untuk mengecek kehadiran ibu hamil atau menyusui dan anaknya yang berusia 0 sampai 6 tahun dalam menghadiri posyandu yang diadakan sebulan sekali. Verifikasi komitmen juga dilakukan ke sekolah-sekolah baik SD, SMP, maupun SMA untuk mengcek kehadiran anak sekolah yang mendapatkan bantuan PKH kategori pendidikan. Hasil verifikasi yang dilakukan oleh pendamping akan menjadi salah satu dasar penyaluran, penangguhan, dan penghentian bantuan pada setiap tahap penyaluran.

\section{g. Pemuthakiran Data}

Pemuthakiran data bertujuan untuk memperoleh kondisi terkini anggota KPM PKH. Hasil kondisi terkini digunakan untuk verifikasi, penyaluran dan penghentian bantuan. Di Nagari Malampah pemuthakiran 
data dilakukan oleh pendamping $\mathrm{PKH}$ sekali 3 bulan. Pemuthakiran data dilakukan untuk melihat apakah keluarga penerima manfaat sudah sejahtera atau masih membutuhkan bantuan. Ketika anak yang sekolah melanjutkan pendidikannya ke yang lebih tinggi misal dari SD ke SMP, maka data tersebut akan berubah. Perubahan data ini untuk memudahkan pendamping dalam melakukan verifikasi ke sekolahnya yang baru.

\section{h. Pengaduan}

Pengaduan digunakan untuk memfasilitasi keluarga penerima manfaat apabila ada permasalahan dalam pelaksanaan $\mathrm{PKH}$ di lapangan dan akan diselesaikan secara berjenjang. Masalah yang ditemui dalam pelaksanaan $\mathrm{PKH}$ di Nagari Malampah diselesaikan dulu oleh ketua kelompok KPM PKH. Apabila ketua tidak bisa menyelesaikannya maka akan dilaporkan ke pendamping kelomok KPM. Pendamping PKH di Nagari Malampah mencoba menyelesaikan masalah yang dilaporkan oleh ketua ataupun anggota KPM dengan kekeluargaan atau didiskusikan dalam kelompok secara musyawarah.

\section{Faktor Penghambat dan Pendukung Implementasi PKH di Nagari Malampah}

Faktor penghambat dan pendukung keberhasilan implementasi PKH dapat dilihat dari empat faktor yaitu komunikasi, sumber daya, sikap pelaksana, struktur organisasi.

\section{Komunikasi}

Komunikasi suatu program hanya dapat dilaksanakan dengan baik apabila jelas bagi para pelaksana (Edward III dalam Deddy 2016:58). Komunikasi yang disampaikan oleh Dinas Sosial kepada petugas dan pendamping $\mathrm{PKH}$ Kabupaten Pasaman sudah baik dan jelas. Informasi yang disampaikan oleh Dinas Sosial berhubungan dengan pelaksanaan PKH di lapangan. Selain itu juga berhubungan dengan penambahan atau pengurangan masyarakat yang menerima bantuan PKH. Namun yang menjadi hambatan dalam pelaksanaan PKH di Nagari Malampah yaitu kurangnya kemampuan keluarga penerima manfaat dalam memahami materi yang disampaikan oleh pendamping PKH. Hal ini terlihat ketika pertemuan kelompok yang mambahas materi lanjutan dari materi sebelumnya, banyak dari keluarga penerima manfaat yang tidak mengingat materi yang disampaikan sebelumnya oleh pendamping PKH. Penyampaian informasi tentang penyaluran dana PKH akan sangat diingat dan dipahami oleh keluarga penerima manfaat.

\section{Sumber Daya}

Menurut Edward III dalam Oktaviani dan Muchtar (2019:264) sumber daya merupakan hal yang penting dalam suatu program atau kebijakan baik itu sumber daya manusia maupun non manusia yaitu meliputi staf dan fasilitas yang cukup dalam menunjang pelaksanaan program. Apabila implementor kekurangan sumber daya maka implementasi tidak akan berjalan efektif (Edward III dalam Alman 2018:4). Berdasarkan data yang diperoleh dan hasil penelitian, sumber daya dalam mendukung keberhasilan 
implementasi Program Keluarga Harapan di Nagari Malampah masih kurang. Hal ini terlihat dari kurangnya tenaga pendamping dan fasilitas yang disediakan untuk pendamping di Nagari Malampah. Pendamping yang ada di Kecamatan Tigo Nagari Masih kurang karena hanya ada 5 pendamping yang mendampingi 67 kelompok keluarga, sehingga dalam pelaksanaannya masih kurang efektif. Selain itu, Kecamatan juga menyediakan kursi dan meja khusus untuk pendamping di Kantor Camat, namun tidak ada ruangan khusus untuk tempat pendamping bekerja melainkan hanya meja dan kursi saja.

3. Disposisi / Sikap Pelaksana

Disposisi merupakan watak dan karakteristik yang dimiliki oleh implementor seperti komitmen, kejujuran dan sikap demoktatis (Edward III dalam Alman 2018:4). Kejujuran mengarahkan implemnetor untuk tetap berada dalam program yang telah digariskan, sedangkan komitmen yang tinggi dari pelaksana kebijakan akan membuat mereka selalu antusias dalam melaksanakan tugas, wewenang, fungsi dan tanggung jawab sesuia peraturan yang ditetapkan (Oktavia, 2018:7).

Sikap pendamping $\mathrm{PKH}$ yang bertugas mendampingi Keluarga Penerima manfaat sudah sesuai dengan ketentuan yang ditetapkan. Hal ini dapat dilihat dari keatifan pendamping dalam mendampingi keluarga penerima manfaat dalam pertemuan kelompok. Namun yang menjadi hambatan dalam keberhasilan implementasi ini yaitu kurangnya kesadaran Keluarga Penerima Manfaat dalam menjalankan kewajibanya sebagai Keluarga Penerima Manfaat
PKH. Hal ini dapat dilihat ketika tidak menghadiri pertemuan kelompok yang diadakan sebulan sekali, terlambat ketika pertemuan berakhir, tidak menghadiri posyandu, tidak menggunakan dana bantuan sebagaimana mestinya seperti dana bantuan untuk pendiikan anak dibelikan ke hal lain yang bukan kebutuhan pendidikan.

\section{Struktur Birokrasi}

Struktur birokrasi berkenaan dengan kesesuaian organisasi birokrasi yang menjadi penyelenggara kebijakan. Struktur Organisasi memiliki pengaruh yang signifikan terhadap implementasi suatu kebijakam (Oktavia, 2018:7) dalam implementasi PKH di Nagari Malampah struktur organisasi sudah baik. Hal ini dikarenakan struktur organisasi dibentuk dari Dinas Sosial Kabupaten Pasaman sehingga jelas bagi pelaksananya. Selain itu juga terdapat Standard Operational Procedur (SOP) yang merupakan perkembangan dari tuntutan internal terhadap kepastian waktu, sumber daya dan kebutuhan penyeragaman dalam organisasi kerja yang kompleks dan luas. Standard Operational Procedur (SOP) dalam pelaksanan Program Keluarga Harapan di Nagari Malampah sudah sesuai dengan SOP (Standard Operating Procedure). Hal ini dapat dilihat dangan adanya buku pendoman pelaksanaan PKH yang selalu dibawa oleh pendamping $\mathrm{PKH}$ dalam melaksanakan tugasnya dilapangan.

\section{KESIMPULAN}

Implementasi Program Keluarga Harapan dalam meningkatkan kesejahteraan keluarga miskin di Nagari Malampah Kecamtan Tigo 
Nagari Kabupaten Pasaman dalam pelaksanaannya sudah berpatokan kepada Peraturan Menteri Sosial Nomor 1 Tahun 2018 dan buku pedoman pelaksanaan Program Keluarga Harapan. Implementasi Program Keluarga Harapan di Nagari Malampah dilihat dari tiga tahapan yaitu tahapan pengorganisasian, interpretasi dan aplikasi atau penerapan. Faktor penghambat dan pendukung keberhasilan implementasi Program Keluarga Harapan dalam meningkatkan kesejahteraan keluarga miskin di Nagari Malampah ada 4 yaitu komunikasi, sumber daya, sikap pelaksana, dan struktur organisasi. Komunikasi dalam menyampaikan informasi dan sosialisasi oleh Dinas Sosial, secretariat PPKH dan pendamping PKH sudah dilakukan dengan baik melalui rapat yang diadakan di kantor Dinas Sosial. Sedangkan informasi dan sosialisasi yang disampaikan oleh pendamping kepada keluarga penerima manfaat juga sudah disampaikan dengan baik, namun masih ada keluarga penerima manfaat yang masih belum memahami informasi yang disampaikan terutama lansia. Sumber daya manusia dan fasilitas dalam pelaksanaan $\mathrm{PKH}$ masih kurang. Sikap pelaksana dalam implementasi PKH sudah sesuai dengan ketentuan yang ditetapkan. Struktur organisasi dalam implementasi PKH di Nagari Malampah sudah sesuai dengan SOP.

\section{DAFTAR PUSTAKA}

Aneta, Asna. 2010. "Implementasi Program Penanggulangan Kemiskinan Perkotaan (P2KP) di Kota Gorontalo. Dosen Universitas Negeri Gorontalo".
Jurnal Adminitrasi Publik, Vol. 1 No. 1 Tahun 2010.

Anggraini, Dian. "Implementasi Program Keluarga Harapan di Kecamatan Sako Palembang". Jurnal Pemerintahan dan Politik Global Vol. 3 Nol. 3 Tahun 2018 (ISSN: 2502-2032)

Erwan Agus Purwanto dan Dyah Ratih Sulistyastuti. 2012.

Implementasi Kebijakan Publik: Konsep dan Aplikasinya di Indonesia. Yogyakarta: Gava Media.

Hikmat, R. Harry. 2017. Pedoman pelaksanaan Program Keluarga Harapan (PKH). Kementerian Sosial RI.

Kasim, Muslim. 2006. Karakteristik kemiskinan di Indonesia dan strategi penanggulangannya. Jakarta. Indomedia

Manongga, Alman, Sofia Pangemanan dan Josef Kairupan. “Implementasi Program Keluarga Harapan dalam mengentas kemiskinan di Kelurahan Pinokalan Kota Bitung". Jurnal Jurusan Ilmu Pemerintahan Vol. 1 No. 1 Tahun 2018 (ISSN:2337-5736)

Mulyadi, Deddy. 2016. Studi kebijakan public dan pelayanan publik. Bandung. Alfabeta.

Nurhadi. 2007. Mengembangkan jaminan sosial Mengentaskan Kemiskinan.Yogyakarta. Media Wacana.

Oktaviani dan Henni Muchtar. 2019. "Implementasi Program Kampung Bantar (Bersih, Aman, dan Pintar di Kelurahan Eka Jaya Kecamatan Paal Merah Kota Jambi". Jurnal Civic Education (ISSN:2622-237X) Volume 2 Nomor 4 Tahun 2019. 
Oktaviani, Resy dan Fatmariza. 2019. "Implementasi Program Keluarga Harapan dalam pengentasan kemiskinan di Pesisir Selatan". Jurnal Civic Education (ISSN:2622-237X) Volume 1 Nomor 2 Tahun 2018. Permana, Arif Citra, Cahyo Sasmito dan Cakti Indra Gunawan. “Implementasi Pemberdayaan Masyarakat dalam Program Keluarga Harapan untuk Memutus rantai kemiskinan di Kota Malang". Jurnal Politik dan Sosial Kemasyarakatan Vol. 10 No. 2 Tahun 2018.

Tirani, Oktavia. "Implementasi Program Keluarga Harapan di Dinas Sosial Kabupaten Poso". Jurnal Katalogis Vol. 5 No. 6 Tahun 2017 (ISSN:2302-2019)

Yunus. $2014 . \quad$ Perencanaan, Implementasi, dan Evaluasi Kebijakan (fungsi-fingsi manajemen). Majalengka. Unit Penerbitan Universitas Majalengka 